\title{
SRSF1 regulates exosome microRNA enrichment in human cancer cells
}

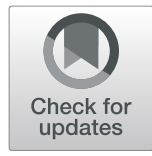

\author{
Yi-Fan Xu', Xiaohui Xu, ${ }^{1,2}$, Amy Gin ${ }^{1}$, Jean D. Nshimiyimana', Blaine H. M. Mooers ${ }^{3}$, Massimo Caputi ${ }^{4}$, \\ Bethany N. Hannafon ${ }^{5,6}$ and Wei-Qun Ding ${ }^{1,6^{*}}$ (D)
}

\begin{abstract}
Background: Exosomes are extracellular vesicles containing a variety of biological molecules including microRNAs (miRNAs). We have recently demonstrated that certain miRNA species are selectively and highly enriched in pancreatic cancer exosomes with miR-1246 being the most abundant. Exosome miRNAs have been shown to mediate intercellular communication in the tumor microenvironment and promote cancer progression. Therefore, understanding how exosomes selectively enrich specific miRNAs to initiate exosome miRNA signaling in cancer cells is critical to advancing cancer exosome biology.

Results: The aim of this study was to identify RNA binding proteins responsible for selective enrichment of exosome miRNAs in cancer cells. A biotin-labeled miR-1246 probe was used to capture RNA binding proteins (RBPs) from PANC-1 cells. Among the RBPs identified through proteomic analysis, SRSF1, EIF3B and TIA1 were highly associated with the miR-1246 probe. RNA immunoprecipitation (RIP) and electrophoretic mobility shift assay (EMSA) confirmed the binding of SRSF1 to miR-1246. Lentivirus shRNA knockdown of SRSF1 in pancreatic cancer cells selectively reduced exosome miRNA enrichment whereas GFP-SRSF1 overexpression enhanced the enrichment as analyzed by next generation small RNA sequencing and qRT-PCR. miRNA sequence motif analysis identified a common motif shared by $36 / 45$ of SRSF1-associated exosome miRNAs. EMSA confirmed that shared motif decoys inhibit the binding of SRSF1 to the miR-1246 sequence.
\end{abstract}

Conclusions: We conclude that SRSF1 mediates selective exosome miRNA enrichment in pancreatic cancer cells by binding to a commonly shared miRNA sequence motif.

Keywords: SRSF1, Exosome, miRNA, miR-1246, Pancreatic cancer

\section{Background}

Exosomes are endosome-derived extracellular vesicles (EVs) [1] that can be transferred from cancer cells to stromal cells in the tumor microenvironment $[2,3]$. These membrane vesicles are $40-120 \mathrm{~nm}$ in size, and contain proteins, lipids and nucleic acids, including

\footnotetext{
* Correspondence: weiqun-ding@ouhsc.edu

'Department of Pathology, University of Oklahoma Health Sciences Center, Oklahoma City, 940 Stanton L. Young Blvd., BMSB 401A, Oklahoma City, OK 73104, USA

${ }^{6}$ Stephenson Cancer Center, University of Oklahoma Health Sciences Center, Oklahoma City, OK 73104, USA

Full list of author information is available at the end of the article
}

small RNAs such as microRNAs (miRNAs) [1, 4]. Exosome-mediated intercellular communication between cancer cells, endothelial cells $[5,6]$, fibroblasts $[7,8]$, or immune cells $[9,10]$ can facilitate tumor progression. Furthermore, cancer exosomes are released into the circulation and contribute to pre-metastatic niche formation in distant organs $[11,12]$.

How cancer exosomes interact with stromal cells to promote tumor progression has been extensively investigated. One critical signaling event in the tumor microenvironment is the exosome miRNA-mediated intercellular communication [1, 13-15]. Studies have shown that exosome miRNA signaling promotes tumor

(c) The Author(s). 2020 Open Access This article is licensed under a Creative Commons Attribution 4.0 International License, which permits use, sharing, adaptation, distribution and reproduction in any medium or format, as long as you give appropriate credit to the original author(s) and the source, provide a link to the Creative Commons licence, and indicate if changes were made. The images or other third party material in this article are included in the article's Creative Commons licence, unless indicated otherwise in a credit line to the material. If material is not included in the article's Creative Commons licence and your intended use is not permitted by statutory regulation or exceeds the permitted use, you will need to obtain permission directly from the copyright holder. To view a copy of this licence, visit http://creativecommons.org/licenses/by/4.0/ The Creative Commons Public Domain Dedication waiver (http://creativecommons.org/publicdomain/zero/1.0/) applies to the data made available in this article, unless otherwise stated in a credit line to the data. 
progression in various model systems [16, 17]. Notably, it has been reported that miRNAs contained in exosomes are delivered to recipient cells in the tumor microenvironment or distant organs where they can regulate target gene expression and promote tumor angiogenesis and metastasis $[13,14,18]$.

In the context of exosome miRNA signaling, we and others have reported that certain miRNA species are selectively enriched in cancer exosomes as compared to exosomes derived from normal epithelial cells [13, 1921]. Results from several studies have also indicated that selective enrichment of exosome miRNAs is relevant to tumor progression [22]. For example, exosome sorting of miR-193a was found to promote colon cancer progression [23]. Likewise, miR-122, a cancer exosome enriched miRNA [19, 24], was shown to reprogram glucose metabolism in a pre-metastatic niche to facilitate metastasis in a breast cancer model system [25]. Moreover, the exosome enriched miR-1246 [26] was reported to promote tumor invasion in both breast cancer [27] and oral squamous cell carcinoma [28]. It seems clear that selective enrichment of exosome miRNAs drives cancer exosome miRNA signaling in the tumor microenvironment, which in turn reinforces tumor invasiveness and progression. However, how exosome miRNAs are enriched or how exosome miRNA signaling is initiated in cancer cells remains largely unknown. Elucidating the mechanisms of selective exosome miRNA enrichment in cancer cells may help identify new cancer therapeutic opportunities that are urgently needed.

Recent reports have indicated that certain RNA binding proteins (RBPs) are involved in exosome miRNA sorting in eukaryotic cells, and the type of RBPs involved seems to differ among various model systems $[23,29,30]$, suggesting that exosome miRNA sorting is a tissue or cell type specific process. Furthermore, there have been no reports on the identification of RBPs that regulate exosome miRNA sorting in pancreatic cancer cells. We have recently characterized the biogenesis of exosome miR-1246 [26], which is the most highly enriched miRNA in pancreatic cancer cell-derived exosomes [21]. The aim of this study was to utilize our established cell model systems to identify RBPs that are involved in exosome miRNA loading in pancreatic cancer cells. Using a labeled miR-1246 probe as "bait", we fished out several RBPs from pancreatic cancer cells, including serine and arginine rich splicing factor 1 (SRSF1), eukaryotic translation initiation factor 3 subunit B (eIF3B), and $\mathrm{T}$ cell-restricted intracellular antigen 1 (TIA1). We found that SRSF1, a recently claimed oncoprotein [31], is predominantly involved in regulating exosome miRNA enrichment in pancreatic cancer model systems.

\section{Methods}

\section{Cell culture}

The human pancreatic cancer cell lines PANC-1, MIAPaCa-2 and BxPC-3, and breast cancer cell line MDA-MB-231 were obtained from the American Type Culture Collection (ATCC, Manassas, VA, USA). Cells were cultured following ATCC's instructions except that exosome-depleted fetal bovine serum (FBS) and horse serum were applied whenever needed. Exosomedepleted FBS and horse serum were prepared by pelleting the serum exosomes at $200,000 \times \mathrm{g}$ for $2 \mathrm{~h}$ at $4{ }^{\circ} \mathrm{C}$. Cells were routinely incubated in a humidified environment at $37^{\circ} \mathrm{C}$ and $5 \% \mathrm{CO}_{2}$.

\section{Exosome isolation}

Exosomes were isolated from the culture medium utilizing a combination of centrifugation, ultracentrifugation, and filtration as we recently described $[13,19,26]$, with minor modifications. In brief, the culture medium of PANC-1 cells was pre-cleared by $10,000 \mathrm{~g}$ centrifugation for $30 \mathrm{~min}$ at $4{ }^{\circ} \mathrm{C}$, and the resulting supernatant was filtered through a $0.22 \mu \mathrm{m}$ PVDF centrifuge filter. The large size EVs were trapped in the filter and recovered in PBS. The filtered supernatant was then applied to a $0.1 \mu \mathrm{m}$ PVDF centrifuge filter. The medium size EVs were trapped in the second filter and re-suspended in PBS. The small size EVs (exosomes) in the final supernatant were recovered by ultracentrifugation $(100,000 \mathrm{~g}$, $70 \mathrm{~min}$ at $4^{\circ} \mathrm{C}$ ). The isolated exosomes were verified by western blot detecting positive and negative exosome marker proteins and nanoparticle analysis (Nanosight NS300 System, Malvern Instruments, UK) measuring both sizes and concentrations of the isolated exosomes (Fig. 1).

\section{miRNA binding protein pull-down}

Pull-down experiment was performed using the Pierce ${ }^{\mathrm{m}}$ Magnetic RNA-Protein Pull-Down Kit (Thermo Fisher Scientific). Briefly, $100 \mathrm{pmol}$ of biotin-labeled miR-1246 or poly-A RNA oligonucleotides (Integrated DNA Technologies) were hybridized to $100 \mu \mathrm{l}$ streptavidin magnetic beads (Prod\#1862766, Thermo Fisher Scientific). The miR-1246-biotin-streptavidin beads were incubated with PANC-1 lysate for $60 \mathrm{~min}$ at $4{ }^{\circ} \mathrm{C}$. The lysate-bead mixture was washed three times with washing buffer from the above-mentioned kit. To elute bound proteins, $50 \mu \mathrm{l}$ of elution buffer was applied, and a magnetic separator was applied to separate the beads from the eluted protein, following the manufacturer's protocol (Pierce ${ }^{\mathrm{Tm}}$ Magnetic RNA-Protein Pull-Down Kit, Thermo Fisher scientific). Proteins were separated by SDS-PAGE before mass spectrometry (MS) analysis. 

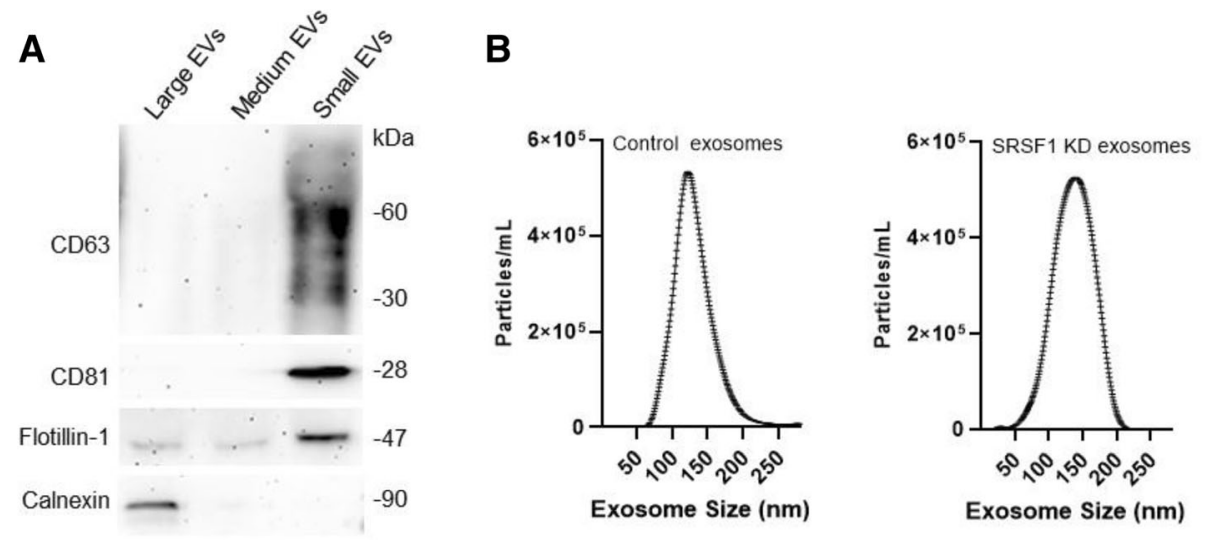

Fig. 1 Verification of the exosomes derived from PANC-1 cells. a Representative western blot analysis of CD63 (non-reducing condition), CD81, flotillin, and calnexin in the EVs isolated from PANC-1 cells. Positive exosome markers are only detected in small EVs (exosomes). b Representative nanoparticle tracking analysis of exosomes (small EVs) derived from control and SRSF1 knockdown PANC-1 cells. Three individual experiments were performed for both $\mathbf{a}$ and $\mathbf{b}$

Liquid chromatography-mass spectrometry (LC-MS)/mass spectrometry (MS) measurement

The experiment was performed by the Laboratory for Molecular Biology and Cytometry Research Core Facility at OUHSC. Proteins were digested with trypsin according to the FASP [32] protocol. Briefly the eluate was buffer exchanged in $8 \mathrm{M}$ urea, the proteins were reduced with $10 \mathrm{mM}$ dithiothreitol and then alkylated with 10 $\mathrm{mM}$ iodoacetamide. The peptides were eluted, dried and resuspended. Liquid chromatography tandem mass spectrometry was performed by coupling a nanaoAcquity UPLC (Waters Corp., Manchester, UK) to a Q-TOF SYNAPT G2S instrument (Waters Corp., Manchester, UK). Each protein digest (about $100 \mathrm{ng}$ of peptide) was delivered to a trap column $(300 \mu \mathrm{m} \times 50 \mathrm{~mm}$ nanoAcquity UPLC NanoEase Column $5 \mu \mathrm{m}$ BEH C18, Waters Corp, Manchester, UK) at a flow rate of $2 \mu \mathrm{l} / \mathrm{min}$ in 99.9\% solvent A $(10 \mathrm{mM}$ ammonium formate $\mathrm{pH} 10$, in HPLC grade water). Tandem mass spectra were generated in the trapping region of the ion mobility cell by using a collisional energy ramp from $20 \mathrm{~V}$ (low mass, start/end) to $35 \mathrm{~V}$ (high mass, start/end). The pusher/ion mobility synchronization for the HDMSe method was performed using MassLynx V4.1 and DriftScope v2.4. LockSpray of Glufibrinopeptide-B (m/z 785.8427) was acquired every $60 \mathrm{~s}$ and lock mass correction was applied post acquisition.

\section{Protein identification}

Raw MS data were processed by PLGS (ProteinLynx Global Server, Waters Corp., Manchester, UK) for peptide and protein identification. MS/MS spectra were searched against the Uniprot Human database (containing 20,417 reviewed sequences) with the following search parameters: full tryptic specificity, up to two missed cleavage sites; carbamidomethylation of cysteine residues was set as a fixed modification; and $\mathrm{N}$-terminal protein acetylation and methionine oxidation were set as variable modifications.

\section{Small RNA library preparation and next generation sequencing}

Total RNA was extracted from cell and exosome pellets using the TRIzol reagent (Invitrogen/Life Technologies, Carlsbad, California). The small RNA libraries were constructed and run on the Illumina MiSeq platform as we recently described $[21,26]$.

\section{RNA immunoprecipitation assay}

PANC-1 cells or MDA-MB-231 cell lysates were prepared using IP buffer (10 mM Tris- $\mathrm{HCl}, \mathrm{pH} 7.4,50 \mathrm{mM}$ $\mathrm{NaCl}, 0.5 \mathrm{mM}$ EDTA, $1 \mathrm{mM}$ PMSF, and $1 \%$ Triton $\mathrm{X}-$ 100). The lysate was sonicated for $1 \mathrm{~min}$ on ice, and insoluble material was removed by centrifugation. Supernatants were collected, and protein concentrations were measured. The supernatant was pre-cleared by Protein G Dynabeads ${ }^{\mathrm{Tm}}$ (Thermo Fisher Scientific), and then mixed with antibody: SRSF1 (Santa Cruz, sc-33,652), EIF3B (Santa Cruz, sc-137,214), TIA1 (Santa Cruz, sc166,247), GAPDH (ProMab, 20,035), and IgG (Santa Cruz sc-2025) in a ratio of $1: 100$ at $4{ }^{\circ} \mathrm{C}$ overnight with gentle rotation. To capture the antibody-protein-RNA complexes, $50 \mu \mathrm{l}$ of protein $\mathrm{G}$ magnetic beads were added, and the complexes were rotated for $2 \mathrm{~h}$ at $4{ }^{\circ} \mathrm{C}$. The sample was separated by magnetic separation. Trizol reagent (Invitrogen/Life Technologies) was applied to isolated RNA from the complex. The miRNA expression was analyzed by qRT-PCR. 


\section{Co-immunoprecipitation (co-IP)}

Co-immunoprecipitation (co-IP) using PANC-1 cell lysate and antibody of SRSF1 (Santa Cruz, sc-33,652), EIF3B (Santa Cruz, sc-137,214), TIA1 (Santa Cruz, sc166,247), GAPDH (ProMab, 20,035), and IgG (Santa Cruz sc-2025) was performed as described previously [33], and the protein complex was detected by western blot.

\section{Western blot analysis}

Western blot was performed as we recently described $[21,26]$. Primary antibodies raised against SRSF1 (Santa Cruz, sc-33,652), EIF3B (Santa Cruz, sc-137,214), TIA1 (Santa Cruz, sc-166,247), beta-actin (A5441), and Glyceraldehyde 3-phosphate dehydrogenase (GAPDH) (Santa Cruz, sc-47,724) were used for detection. Nuclear and cytoplasmic protein extraction was extracted following ROCKLAND Nuclear \& Cytoplasmic Extract Protocol [34], and verified by Histone-H3 (CST, 4499S) and GAPDH (Santa Cruz, sc-47,724) detection. Antibodies used for exosome marker detection include: CD63, CD81 (Santa Cruz Bio Technology Inc., CA, USA), Flotillin-1 and Calnexin (Cell Signaling Technology, Inc., MA, USA).

\section{Quantitative real-time reverse transcription polymerase chain reaction (qRT-PCR)}

qRT-PCR was performed as we described [21, 26] with specific primers: Cel-54 (5'-GCGCGCCCGTAATCTT CATAATCC-3'), miR-1246 (5'-GCGCGATGGATTTT TGGAGCAG-3'), miR-320c (5'-GCAAAAGCUGGGUU GAGAGGGU-3'), and miR-320d (5'-GCGAAAAGCU GGGUUGAGAGGA-3').

\section{SRSF1 shRNA expression plasmid construction}

Target specific oligonucleotides were designed using online tool RNAi Codex (Cold Spring Harbor Laboratory), and were synthesized (Integrated DNA Technologies) with the addition of overhangs according to the cutting site of BamH1 and EcoRI. The shRNA expression plasmid was constructed by annealing the oligonucleotides to $\mathrm{pSIH}-\mathrm{H} 1$ vector following the user manual of $\mathrm{pSIH}$ H1 shRNA system (SBI system Bioscience). The oligonucleotide sequences for shRNA of SRSF1, EIF3B or TIA1 are provided in Supplemental Table 1.

\section{Lentivirus transduction}

Lentiviral particles were produced as previously described [35] using the shRNA expression plasmid and the 3rd generation packaging plasmids pMD2.G (Addgene plasmid \#12259), pMDL/RREg/p (Addgene plasmid \#12251), and pRSV-Rev (Addgene plasmid \#12253). The packaging plasmids were co-transfected with the lentiviral expression vector into $293 \mathrm{~T}$ cells using the polyethyleneimine (Polysciences Inc.) to produce replication deficient lentivirus. After transfection, the supernatant was pooled and filtered with a $0.45 \mu \mathrm{m}$ membrane and concentrated by ultracentrifugation to acquire lentivirus. Infection was performed by using lentivirus in the presence of $8 \mu \mathrm{g} / \mathrm{ml}$ polybrene (SigmaAldrich). Approximately $48 \mathrm{~h}$ post-infection cells were selected by treating with $10 \mu \mathrm{g} / \mathrm{ml}$ puromycin (InvivoGen, San Diego, CA).

\section{GFP-SRSF1 expression}

The GFP-SRSF1 expression plasmid was a gift from Dr. Massimo Caputi [36]. DNA transfection was performed using Lipofectamine 3000 (Thermo Fisher Scientific) to PANC-1 cells and the expression of GFP-SRSF1 was verified by western blot.

\section{GST-SRSF1 protein purification}

BL21 (Thermo-Fisher Scientific, C600003) competent cells transformed with pGEX6P-SRSF1 DNA (Addgene plasmid \# 99020, [37] were cultured at $37^{\circ} \mathrm{C}$ for $3.5 \mathrm{~h}$, and after OD600 reached to 0.6-0.8, bacteria were treated with $0.1 \mathrm{mM}$ isopropyl $\beta$-D-1-thiogalactopyranoside for $24 \mathrm{~h}$ at $16^{\circ} \mathrm{C}$. GST-tagged-SRSF1 was purified with Glutathione Sepharose beads (GE Health Care). The purity of the recombinant proteins was determined by SDS-PAGE with Coomassie blue staining.

\section{Electrophoretic mobility shift assay (EMSA)}

IRD-800 labeled miR-1246 $(0.1 \mu \mathrm{M})$ (Integrated DNA Technologies) was mixed with $4 \mu \mathrm{l}$ of GST slurry, or GST-SRSF1 in binding buffer (Tris pH $8.040 \mathrm{mM}$, KCL $30 \mathrm{mM}, \mathrm{MgCL} 21 \mathrm{mM}$, NP40 0.001\%, DTT $1 \mathrm{mM}$, glycerol 5\%) and incubated at room temperature for $40 \mathrm{~min}$ avoiding light. 5X loading buffer (KCL $60 \mathrm{mM}$, Tris $\mathrm{PH}$ $7.610 \mathrm{mM}$, glycerol $10 \%$, xylene cyanol $0.01 \%$, bromophenol blue $0.01 \%$ ) was then added, and the complex was separated on a $4 \%$ native gel (40\% polyacrylamide, 1 $\mathrm{M}$ Tris $\mathrm{pH} 7.5,1 \mathrm{M}$ glycine, $0.5 \mathrm{M}$ EDTA, $10 \%$ APS, TEMED) at 120 voltage for $40 \mathrm{~min}$. The signal was detected using the Li-Cor Odyssey 9120 Imaging system (LI-COR. Inc., USA).

\section{Design of decoy motif mimics}

The decoy motif mimics were designed by permutation and combination of the identified motif sequences in the length of 24 nucleotides. The secondary structure of the designed sequences was analyzed in RNAfold WebServer (University of Vienna). Sequences without selfcomplementary were selected (Decoy mimics 1: $5^{\prime}$-UU GGACUAGGACUAGGAU-3', Decoy mimics 2: 5'AGGAAGGAAGGAAGGA-3'). 


\section{Bioinformatics analysis}

The miRNA motif analysis was performed using MEME Suite [38]. The protein profile analysis for the result of mass spectrometry was performed using DAVID Bioinformatics (ABCC at SAIC-Frederick, Inc). The RNA binding protein and miRNA sequence binding analysis was performed using the database of RNA-binding specificities (RBPDB) [39]. SRSF1 expression in cancer tissues was examined using ONCOMINE [40]. The correlation of gene expression with cancer patient survival was extracted from The Human Protein Atlas (SciLifeLab, Sweden) [41].

\section{Statistics}

Statistical analyses were performed using GraphPad Prism software (GraphPad Software, Inc. La Jolla, CA, USA). The heatmap was made in RStudio (RStudio, Inc) with the ggplot2 package [42]. Student's t-test was applied to determine significant differences among control and experimental groups.

\section{Results}

\section{Identification of miR-1246 associated proteins}

Because RBPs are involved in exosome miRNA sorting, we first sought to identify proteins that bind to miRNAs highly enriched in cancer exosomes. miR-1246, the most highly enriched miRNA in pancreatic cancer exosomes, was biotin-labeled and incubated with a cellular lysate from PANC-1 cells. The biotin-miR-1246 probe was captured with streptavidin-coated magnetic beads. Biotin labeled poly-A mimics were used as control. The miRNA-protein complexes were eluted and the proteins were analyzed by liquid chromatography/mass spectrometry in triplicate (Table 1). There were total of 593 proteins specifically pulled down by the miR-1246 probe. Interestingly, about half of the proteins that associate with miR-1246 are vesicle-associated proteins (Supplement Fig. 1A). Based on the intensity of detection, RNA binding property, and cancer relevance, we ranked the RBPs using "The Database for Annotation, Visualization and Integrated Discovery (DAVID)". This resulted in ten candidate RBPs that complex with the miR-1246 sequence and are relevant to eukaryotic exosomes (Table 2). Among them, SRSF1 (also called SFRS1) was predicted to bind to the miR-1246 sequence

Table 1 Over view of the result of mass spectrometry

\begin{tabular}{ll}
\hline Experiments' condition & Number of proteins detected \\
\hline Poly A + PANC-1 & 575 \\
Poly A + MDA-MB-231 & 609 \\
miR-1246 + PANC-1 & 793 \\
miR-1246 + MDA-MB-231 & 582 \\
\hline
\end{tabular}

Table 2 miR-1246 RNA binding protein candidates obtained from the mass spectrometric analysis

\begin{tabular}{ll}
\hline Protein symbol & Protein full name \\
\hline SRSF1 & Serine/arginine-rich splicing factor 1 \\
PARK7 & Parkinson disease protein 7 \\
EIF3B & Eukaryotic translation initiation factor 3 subunit B \\
THOC4 & THO complex subunit 4 (Aly/REF export factor) \\
ACOC & Cytoplasmic aconitate hydratase \\
DDX5 & Probable ATP-dependent RNA helicase DDX5 \\
TIA1 & T-cell-restricted intracellular antigen-1 \\
IF5A1 & Eukaryotic translation initiation factor 5A-1 \\
EIF2A & Eukaryotic translation initiation factor 2A \\
IMDH2 & Inosine-5'-monophosphate dehydrogenase 2 \\
\hline
\end{tabular}

(Supplement Fig. 2) by in silico analysis using the database of RNA-binding specificities (RBPDB) [39].

\section{Verification of SRSF1 binding to miR-1246}

RNA immunoprecipitation (RIP) was performed to verify the association of several identified RBPs with miR-1246, including SRSF1, EIF3B and TIA1. IgG and GAPDH antibody was used as controls for immunoprecipitation. As shown in Fig. 2a, miR-1246 expression is more than 12-fold higher in the SRSF1-precipitants, as compared to that of IgG precipitants, indicating a specific association of SRSF1 with miR-1246. miR-1246 expression was moderately increased in the TIA1-precipitants, and near IgG control levels in the EIF3B precipitants. CoImmunoprecipitation (Co-IP) experiments were performed to verify the immunoprecipitation procedures (data not shown). To directly determine the binding of SRSF1 to the miR-1246 sequence, glutathione stransferase (GST) conjugated human SRSF1 protein was expressed in BL21 competent E. coli, captured by glutathione sepharose beads, and eluted by glutathione. The purity of eluted GST-SRSF1 protein was shown by SDSPAGE and Coomassie blue staining (Supplement Fig. 3).

The binding of GST-SRSF1 to a fluorescent-tagged miR-1246 probe was determined by RNA EMSA. As shown in Fig. 2b, binding of the labeled probe was specific to GST-SRSF1, but not GST, and increased with greater protein input. The specific binding of GSTSRSF1 to the miR-1246 probe was evident as the unlabeled miR-1246 probe effectively competed with the labeled miR-1246 probe in a concentration-dependent manner (Fig. 2c). The detected bands were semi- quantified and the $K_{d}$ was calculated from the detected signals (Fig. 2d). These data confirmed the direct binding of SRSF1 to the miR-1246 sequence. 
A

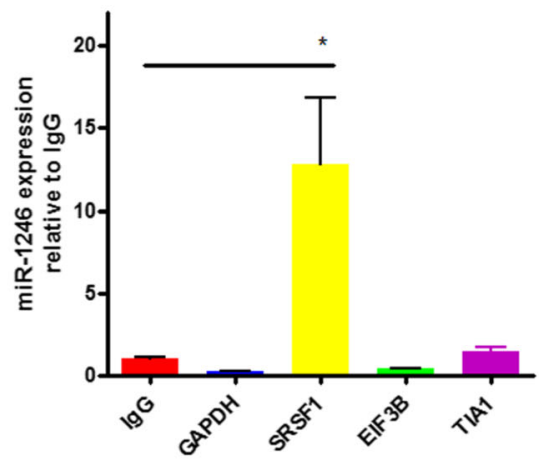

C $\begin{array}{lccccccc}\text { GST-SRSF1 }(\mu \mathrm{g}) & 5 & 5 & 5 & 5 & 5 & 5 & 5 \\ \text { Cold probe }(\mu \mathrm{M}) & - & 0.03 & 0.1 & 0.3 & 0.9 & 1.8 & 2.7\end{array}$

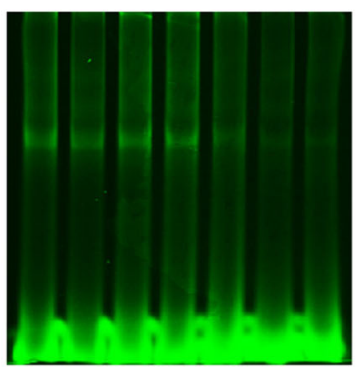

\section{B}

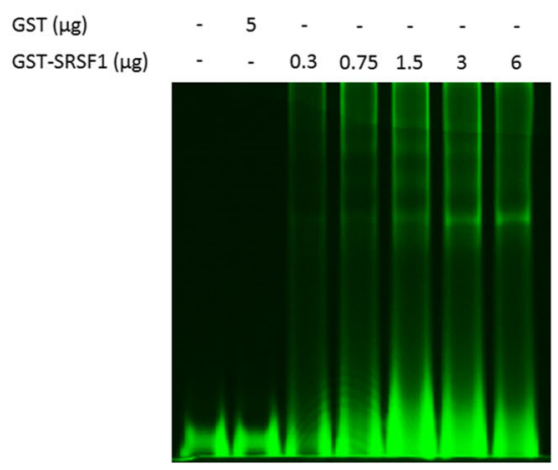

D

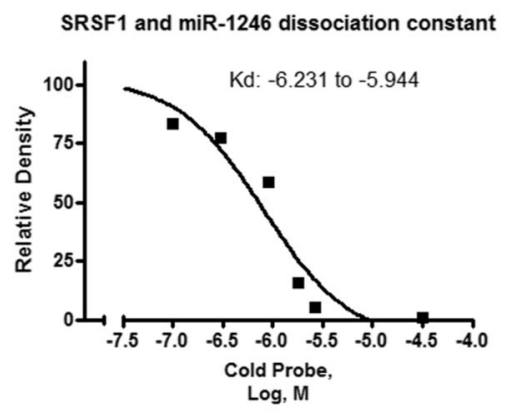

Fig. 2 SRSF1 binds to miR-1246. a qRT-PCR detection of miR-1246 in IgG, GAPDH, SRSF1, EIF3B, and TIA1 immunoprecipitants of PANC-1 lysate ( $n=3,{ }^{*} p<0.001$, student t-test). b-c EMSA detection of the SRSF1-miR-1246 complex (hot probe: IRD-800 labeled miR-1246 mimics; cold probe: miR-1246 mimics, $n=3$ ). Direct binding of GST-SRSF1 and miR-1246 (b); and concentration-dependent competition between the cold and hot miR-1246 probe for binding to GST-SRSF1 (c). d Semi-quantification of SRSF1 and miR-1246 binding in $\mathbf{C}$ and calculated dissociation constant $(n=3)$

\section{Exosome miRNA enrichment by SRSF1 in cancer cells}

Because SRSF1 is a key splicing factor that is essential to eukaryotic cells [31], a knockout model could not be established. Therefore, to determine whether SRSF1 miRNA binding activity is relevant to exosome miRNA enrichment, we established a lentivirus SRSF1 shRNA construct to knockdown SRSF1 expression in PANC-1 cells (Fig. 3a). Interestingly, though SRSF1 protein was detected both in the nucleus and cytoplasm, the knockdown was more pronounced in the cytoplasm (Fig. 3b). Knockdown of SRSF1 did not significantly alter the concentration and size distribution of the exosomes released by PANC-1 cells (Fig. 1b). Cellular and exosome RNA from control and SRSF1-shRNA cells were isolated and small RNA sequencing was performed. Among the 58 highly enriched PANC-1 exosome miRNAs, expression of 45 miRNAs (77.6\%) was significantly down-regulated in exosomes derived from SRSF1-shRNA PANC-1 cells as compared to exosomes derived from control PANC-1 cells (Fig. 3c), strongly indicating the involvement of SRSF1 in exosome miRNA enrichment. A heatmap showing the expression of the top 25 miRNAs enriched in PANC-1 exosomes demonstrates the dramatic drop in expression levels of miRNAs in SRSF1-shRNA PANC-1 exosomes compared to PANC-1 exosomes (Fig. 3d). Notably, miR-1246 was the highest enriched exosome miRNA (data not shown) and its expression in exosomes was significantly reduced by SRSF1 knockdown (Fig. 3d). On the other hand, among 51 of the miRNAs less enriched in exosomes, only 18 $(35.3 \%)$ were expressed at lower levels in exosomes derived from SRSF1 knockdown cells as compared to exosomes derived from wild type PANC-1 cells (Fig. 3c), suggesting that SRSF1 knockdown mainly affects exosome enriched miRNAs.

To further confirm the effect of SRSF1 knockdown on exosome miRNA enrichment, the expression levels of several representative miRNAs were quantified by qRTPCR. SRSF1 knockdown in PANC-1 cells significantly reduced exosome levels of miR-1246, miR-320c and miR-320d, confirming the small RNA sequencing results (Fig. 3e). In contrast, knockdown of EIF3B or TIA1 did not reduce exosome miR-1246 expression, suggesting that these RBPs may not promote exosome miRNA 
A

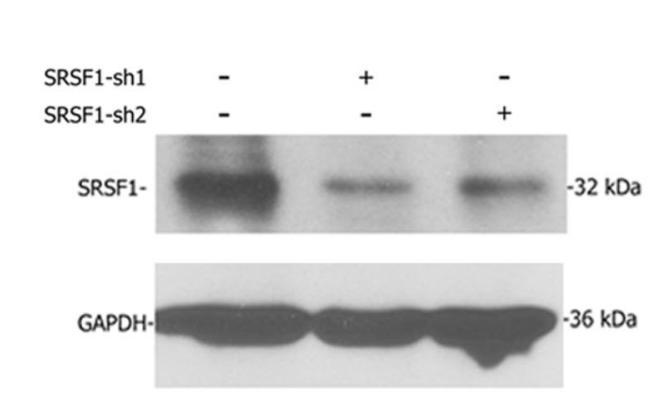

C

miRNAs highly enriched in PANC-1 exosomes versus PANC-1 cells

miRNAs highly enriched in PANC-1 cells versus PANC-1 exosome

miRNAs whose level is reduced in SRSF1-knockdown PANC-1 exosomes versus PANC-1 exosomes

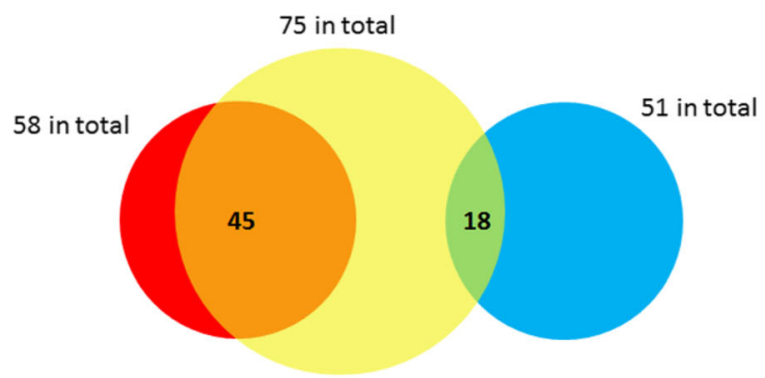

D

E

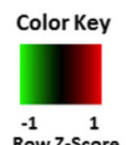

$\begin{array}{cc}-1 & 1 \\ \text { Row } & 1 \\ -S c o r e\end{array}$

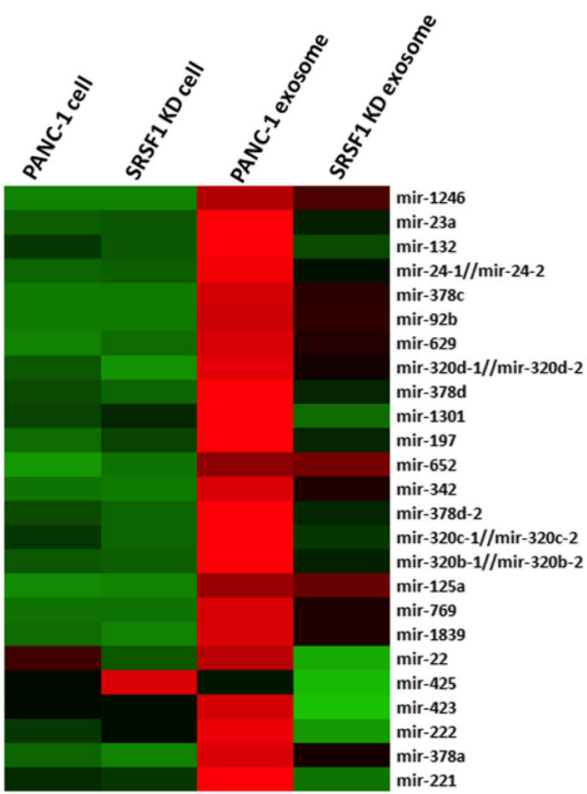

B

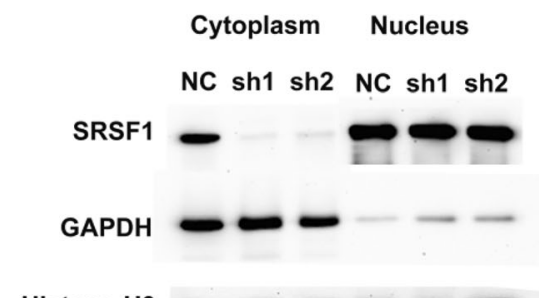

Histone-H3 - - - - 
(See figure on previous page.)

Fig. 3 Cellular and exosome miRNA profiles after SRSF1 knockdown in PANC-1 cells. a Detection of SRSF1 knockdown by shRNAs in PANC-1 cells. b PANC-1 SRSF1 protein levels in nuclear and cytoplasmic fractions (NC: normal control). c Venn Diagram of overlap of miRNAs detected by next generation small RNA sequencing in SRSF1 knockdown and control PANC-1 cells and exosomes. $\mathbf{d}$ Heatmap showing the expression of top 25 exosome miRNAs in cells and exosomes after SRSF1 knockdown. e qRT-PCR analysis of miR-1246, miR-320c and miR-320d in exosomes derived from control and SRSF1 knockdown PANC-1 cells ( ${ }^{*} p<0.001$, Student's t-test). Shown are representatives of three independent experiments (a-e)

enrichment (Supplement Fig. 4 and 5). Our observations were extended to two additional pancreatic cancer cell lines, MIAPaCa-2 and BxPC-3 (Fig. 4a-f). In addition, expression of let-7c, which is less enriched in exosomes, was unchanged in exosomes after SRSF1 knockdown (data not shown).

To verify the involvement of SRSF1 in exosome miRNA enrichment in cancer cells, we also exogenously overexpressed SRSF1 in PANC-1 cells. A GFP-SRSF1 expression plasmid was introduced into PANC-1 cells, and SRSF1 over-expression was confirmed by western blot (Fig. 5a). Expression of miR-1246, miR-320c, and miR$320 \mathrm{~d}$ in the exosomes derived from GFP-SRSF1 PANC-1 cells was analyzed by qRT-PCR (Fig. 5b-c). As shown in Fig. 5b, over-expression of GFP-SRSF1 increased exosome expression of miR-1246 and rescued miR-1246 levels in exosomes derived from SRSF1-shRNA cells. Levels of miR-320c and miR-320d were also increased in exosomes derived from the GFP-SRSF1 cells, further supporting the involvement of SRSF1 in exosome miRNA enrichment (Fig. 5c-d).

\section{Identification of RNA sequence motifs involved in exosome miRNA enrichment}

According to the RBPDB, SRSF1 binds specifically to a motif present in the miR-1246 sequence (Supplement

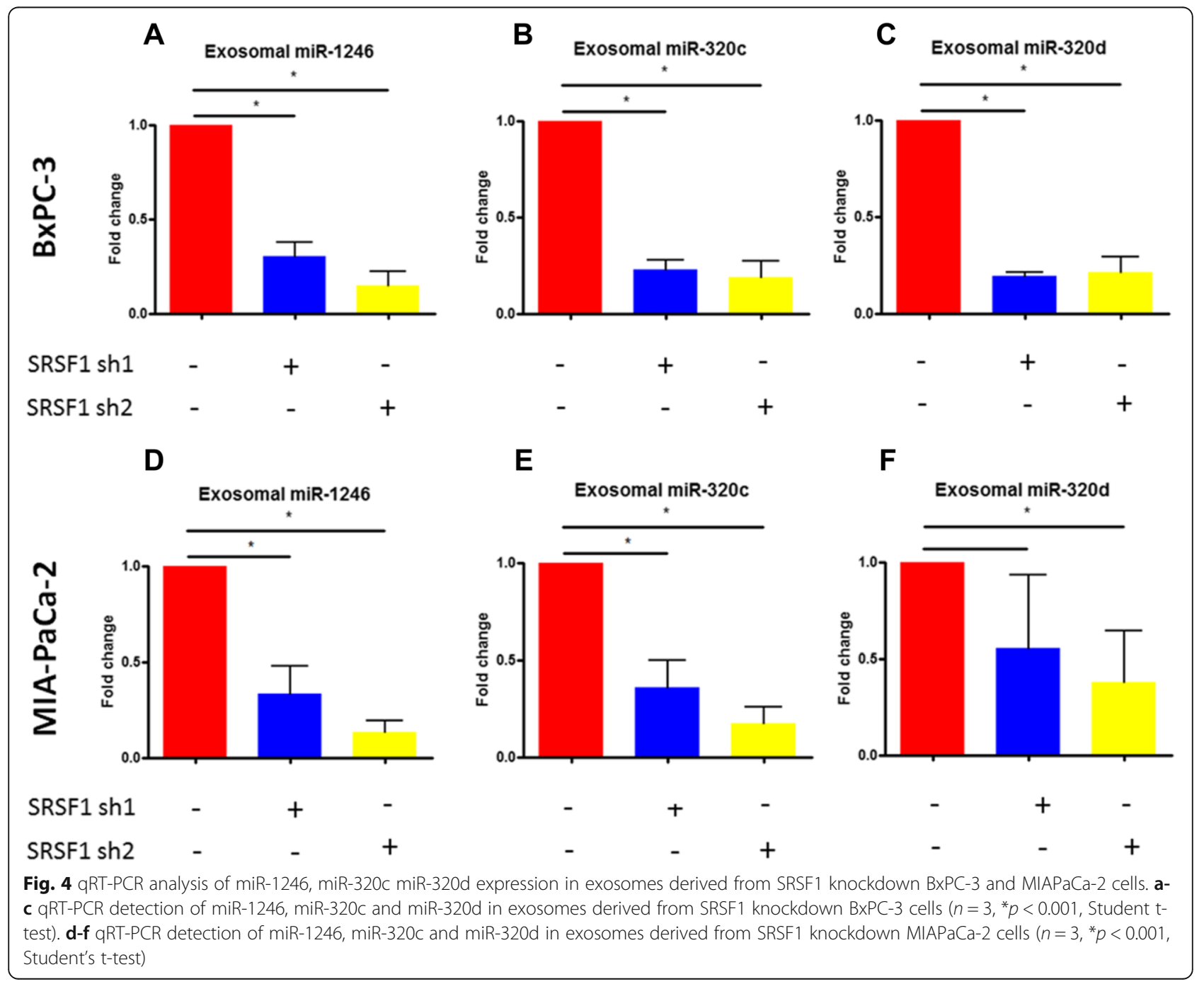


A

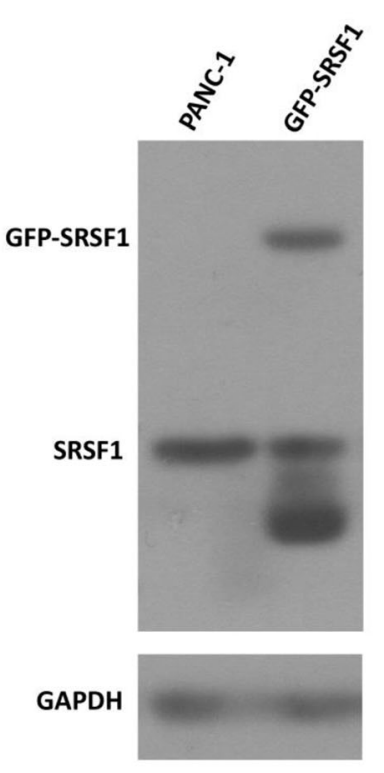

C

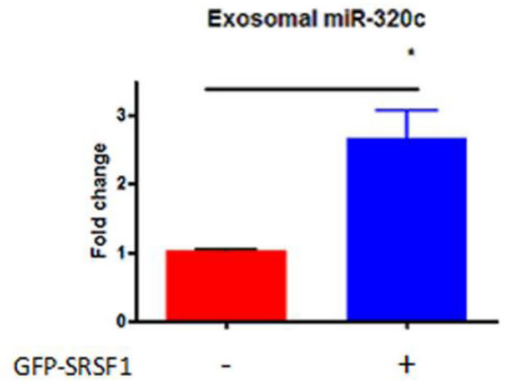

B

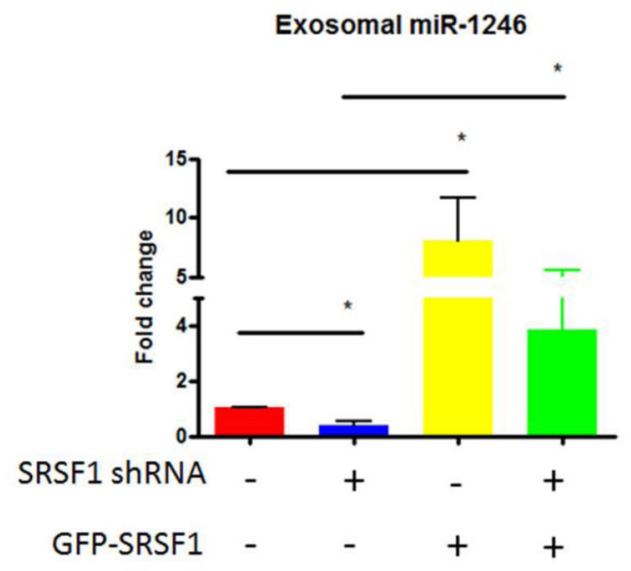

D

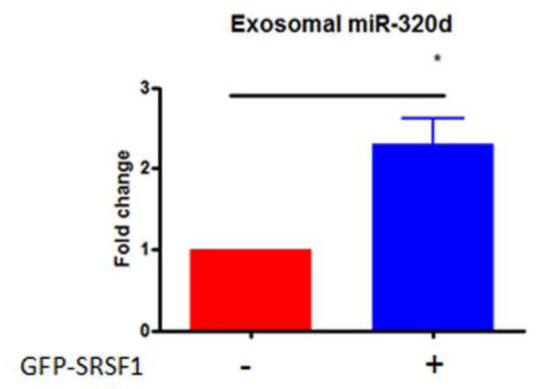

Fig. 5 qRT-PCR analysis of exosome enriched miRNAs derived from SRSF1 overexpression PANC-1 cells. a Confirmation of GFP-SRSF1 overexpression in PANC-1 cells. $\mathbf{b}$ qRT-PCR detection of miR-1246 in exosomes derived from wild type and SRSF1 knockdown PANC-1 cells with GFP-SRSF1 overexpression. $\mathbf{c}$ qRT-PCR detection of miR-320c in exosomes derived from GFP-SRSF1 overexpression PANC-1 cells. $\mathbf{d}$ qRT-PCR detection of miR-320d in exosomes derived from GFP-SRSF1 overexpression PANC-1 cells. ${ }^{*} p<0.001$, Student's t-test, $n=3$ for (b-d)

Fig. 2). To understand the contribution of specific RNA motifs involved in exosome miRNA enrichment, we applied an unbiased approach to identify the RNA motifs that contribute to exosome miRNA enrichment. For this purpose, we analyzed the RNA sequences of the miRNAs highly enriched in cancer exosomes and regulated by SRSF1, using the bioinformatics tool MEME Suite [38]. A 6-bp length motif was found to be shared in 36 of the 45 exosome enriched miRNAs, including miR1246 (Fig. 6 A-C). To test whether the binding of SRSF1 to miR-1246 depends on this motif, two decoy mimics were designed according to the shared motif sequences and their secondary structure (determined with the RNAfold WebServer, http://rna.tbi.univie.ac.at/cgi-bin/ RNAWebSuite/RNAfold.cgi). The binding of the decoy mimics to SRSF1 protein was determined by RNA
EMSA analysis. Addition of decoy motif \#1 did not alter the binding of SRSF1 to the miR-1246 probe (Fig. 6d), whereas decoy motif \#2 competed with miR-1246 binding to SRSF1 in a concentration-dependent manner (Fig. 6d-f), indicating that SRSF1 directly interacts with this sequence motif.

\section{Discussion}

The role of exosome miRNA signaling in promoting cancer progression has been intensely investigated and well recognized in recent years $[43,44]$. The higher enrichment of certain miRNAs in cancer exosomes [13, 19-21] indicates that exosome miRNA encapsulation is an active cellular process that initiates exosome miRNA signaling in the tumor microenvironment. However, the specific cellular process responsible for selective 
A

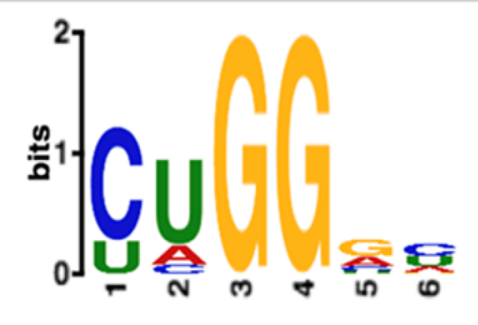

\section{C}

\section{miRNA name miRNA sequence}

mir-502 AAUGCAC CUGGGC AAGGAUUCA

\begin{tabular}{|l|l|l|l}
\hline mir-378g & A & CUGGGC \\
\hline
\end{tabular} \begin{tabular}{|l|l|l}
\hline mir-769 UGAGACCD CUGGGU UCUGAGCU &
\end{tabular}

mir-7689 GCCAGACUG CUGGGU DO

mir-320d-1//mir-320d-2 AAAAG CUGGGD DGAGAGGA

mir-320c-1//mir-320c-2 AAAAG CUGGGU UGAGAGGGU

mir-320b-1//mir-320b-2 AAMAG CUGGGU UGAGAGGCA

mir-222 CAUCUGGCU CUGGG

\begin{tabular}{l|l} 
mir-221 ACAUUGUCU CUGGG UUC &
\end{tabular}

\begin{tabular}{l|lll}
\hline mir-422a & A & CUGGAC UUAGGUCAG
\end{tabular}

\begin{tabular}{l|l|l|l}
\hline mir-378i & A & CUGGAC UAGGAGUCAG
\end{tabular}

\begin{tabular}{l|l|l|l}
\hline mir-378d-2 & A & CUGGAC & UUGGAGUCAC \\
\hline
\end{tabular}

mir-378C A CUCGAC UDGGAGDCAG

\begin{tabular}{l|ll} 
mir-378a & A & CUGGAC DUGGAGUCAG
\end{tabular}

\begin{tabular}{|l|l|l}
\hline mir-1301 & UUGCAGCUG CUGGGA GUGACUUC
\end{tabular}

\begin{tabular}{|l|l|l|l}
\hline mir-378d & A & CUGGCC & UUGGAGUCAG \\
\hline
\end{tabular}

mir-193b $\quad$ AA CUGCCC CDCAAAGUCC

\begin{tabular}{c|c|c|} 
mir-421 CAGACAUUA UUGGCC GC &
\end{tabular}

\begin{tabular}{l|lll}
\hline mir-149 & O & CUGGCU & CCGUGUCUUC \\
\hline
\end{tabular}

mir-1296 UUAGGGCC CUGGCU CCAUCUCC

mir-345 ACUCCUAGU CAGGG UC

\begin{tabular}{l|l}
\hline mir-6239 & UAGCG UDGGAD CACUCGGUG
\end{tabular}

\begin{tabular}{|l|l|l}
\hline mir-629 & UGGGUUUACUDGGGA GAACD
\end{tabular}

mir-505 UCAACACUU CUGGUD UCCO

mir-125a GGUGAGGUUUOGGGA GCC

mir-501 AAUGCAC CCGGGC AAGGAUUCU

\begin{tabular}{l|l} 
mir-23a AUCACAUUG CAGGGA UUUCC \\
\hline mir-576
\end{tabular}

mir-576 UGUGGAAA UUGGAA DC

mir-24-1//mir-24-2 CUCAGUUCA CAGGAA CAG

mir-1983 CUCAC CUGGAG CAUGUUUUCU

\begin{tabular}{l|l} 
mir-652 & AUGGCGCCA UAGGGO UGUG
\end{tabular}

\begin{tabular}{l|l} 
mir-3200 UUGCGCUACCAGGUC UG \\
\hline
\end{tabular}

mir-1839 GUAGAUAGACAGGUC UUG

mir-92a-2//mir-92a-1 UGCACUUGU CC CCC DG

mir-1246 AAUGGAUUUUUGGAG CAGG

\begin{tabular}{l|l|l|l}
\hline mir-425 & AAUGGAUUU UUGCAG & CAGG \\
\hline & A & UCGGGA & AUGUCGUGUC
\end{tabular}

$\mathbf{E}$

$\begin{array}{llllllll}\text { GST-SRSF1 }(\mu \mathrm{g}) \quad 5 & 5 & 5 & 5 & 5 & 5 & 5 & 5\end{array}$

$\begin{array}{llllllll}\text { Decoy mimics } 2(\mu \mathrm{M}) & - & 0.03 & 0.1 & 0.3 & 0.9 & 1.8 & 2.7\end{array}$

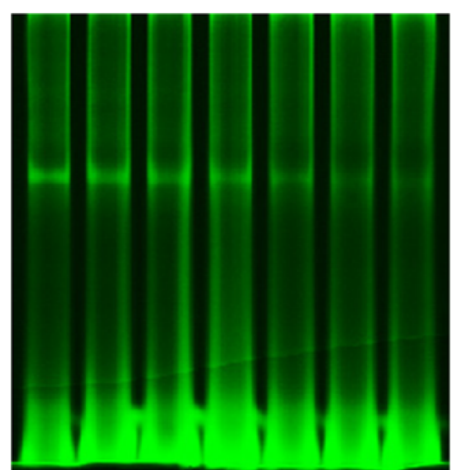

B
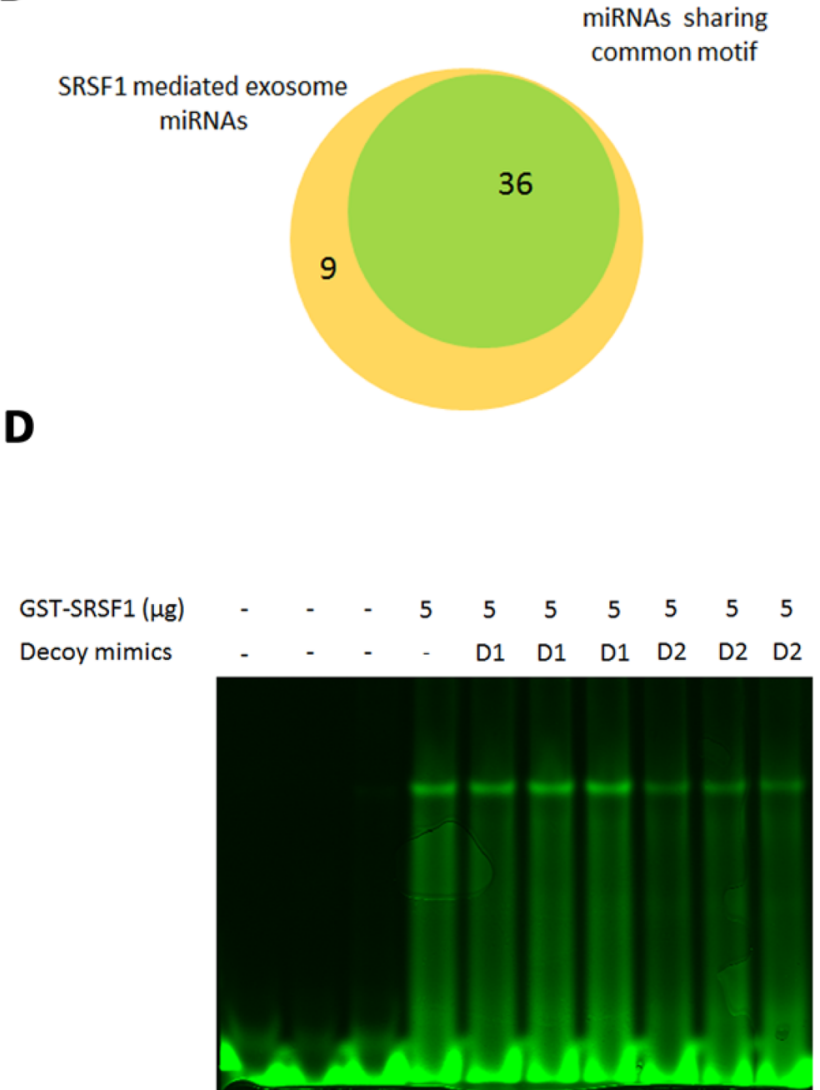

$\mathbf{F}$

Decoy mimics 2 competes with miR-1246's binding to SRSF1

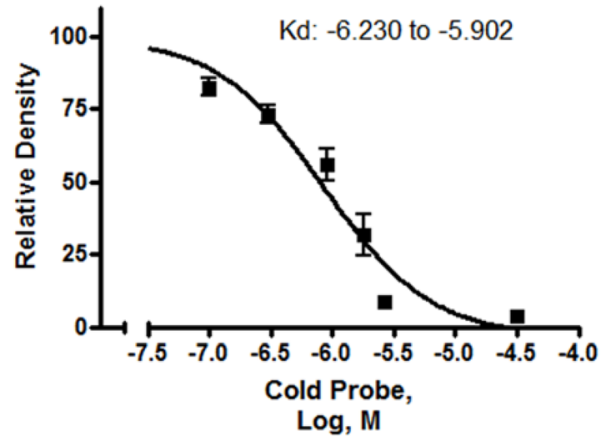

Fig. 6 (See legend on next page.) 
(See figure on previous page.)

Fig. 6 SRSF1-associated exosome miRNA sequence motif analysis. a The motif commonly shared among SRSF1-associated exosome miRNAs. b Venn diagram showing the number of SRSF1-associated exosome miRNAs that share the motif. $\mathbf{c}$ List of miRNAs sharing the common motif. $\mathbf{d}$ EMSA analysis demonstrating the inhibition of GST-SRSF1 binding to miR-1246 by RNA decoys (D1: decoy 1, 5'-UUGGACUAGGACUAGGAU-3'; D2: decoy 2, 5'-AGGAAGGAAGGAAGGA-3'). e Concentration-dependent inhibition of GST-SRSF1 binding to miR-1246 by D2. f Semi-quantification of the detected bands in Fig. 5e and the calculated dissociation constant

exosome miRNA enrichment has not been well established in eukaryotic cells. The most significant finding from the present study is that we have identified SRSF1 as a mediator of exosome miRNA enrichment in pancreatic cancer cells. A specific miRNA sequence motif was also identified that may be involved in the exosome miRNA enrichment process. These findings provide new insight into how miRNAs are enriched in cancer cell exosomes to initiate exosome-mediated miRNA signaling.

We recently reported that exosome miR-1246, the most highly enriched miRNA in pancreatic cancer cellderived exosomes [21], is derived from RNU2-1, a small nuclear RNA important for mRNA splicing [26]. Along this line of our research, we sought to determine how this miRNA is enriched in cancer exosomes using our established model systems. In the present study, we have provided several lines of evidence demonstrating that SRSF1, a vital splicing factor [45] and established oncoprotein [46], is significantly involved in exosome miRNA enrichment in pancreatic cancer cells. The first line of evidence indicating SRSF1 involvement in exosome miRNA enrichment was obtained from the biotinlabeled miR-1246 pull-down experiment, followed by proteomic analysis. Among the RBPs identified, several were selected based on their detection intensity, relevance to extracellular vesicles, and reported connections to human cancer [40], including SRSF1, EIF3B, and TIA1. Of note, SRSF1 was the only RBP among them that was also predicted by the RBPDB to bind to a motif in the miR-1246 sequence. Furthermore, the direct binding of SRSF1 to the miR-1246 sequence was verified by RIP and RNA EMSA analysis, strongly indicating the physical interaction of SRSF1, and not EIF3B or TIA1, with the miR-1246 sequence. The most convincing evidence demonstrating the involvement of SRSF1 in cancer exosome miRNA enrichment was the observation that knockdown of SRSF1 significantly reduces exosome miRNA enrichment for a majority of the selectively enriched exosome miRNAs, without altering the expression levels of less enriched exosome miRNAs. These results were based on small RNA sequencing and confirmed by RT-PCR analysis. The observations were also extended to additional human pancreatic cancer cell lines, including MIAPaCa-2 and BxPC-3.

SRSF1 was initially identified as a splicing factor in eukaryotic cells [45], but SRSF1 was later revealed to shuttle between the nucleus and cytoplasm [47] to regulate RNA metabolism, miRNA procession [48] and other cellular events independent of the mRNA splicing process [31]. Importantly, SRSF1 is over-expressed in different cancer types and is considered a potent oncogene [46, 49]. Moreover, SRSF1 over expression in different types of cancer is associated with worse prognosis (Supplement Fig. 6). While the full spectrum of SRSF1 function remains to be determined, our results reveal that SRSF1 binds to specific miRNAs and is significantly involved in exosome miRNA enrichment in cancer cells. This function is likely independent of the splicing process as the reduced expression of the detected exosome miRNAs after SRSF1 knockdown is greater than their expression change in the cells. Because exosome miRNA signaling contributes to tumor development through intercellular communication in the tumor microenvironment $[6,50,51]$, the involvement of SRSF1 in exosome miRNA signaling initiation likely represents a part of its oncogenic action, which may lead to new therapeutic strategies to intervene with exosome miRNA signaling in cancer. Several RBPs have been previously identified as mediators of exosome miRNA sorting in various model systems, including major vault protein in colon cancer cells [23], hnRNPA2B1 [29] in T cells, and YBX1 in HEK293T cells [30]. The identification of SRSF1 involvement in exosome miRNA enrichment in pancreatic cancer cells further supports the notion that the cellular exosome miRNA sorting process in eukaryotic cells may differ among different cell types.

We have also identified a miRNA motif commonly shared by the SRSF1-associated exosome miRNAs using the MEME Suite program (meme-suite.org). This motif was specifically bound by SRSF1 as evidenced by our RNA EMSA analysis. A similar motif, albeit slightly shorter, was identified in our recent report that describes exosome miR-1246 enrichment in pancreatic cancer cells [26]. Our results reinforce the concept that specific miRNA motifs are involved in exosome miRNA sorting [29]. The fact that a decoy motif was able to compete with the miR-1246 probe for binding to SRSF1 indicates a possibility that decoy motifs can be applied to alter exosome miRNA enrichment or exosome miRNA signaling in cancer cells. This assumption merits further investigation. 


\section{Conclusions}

In summary, we have demonstrated that SRSF1 binds to a specific motif in the miR-1246 sequence and is significantly involved in selective exosome miRNA enrichment in cancer cells. These findings reveal new insights into our understanding of the cellular process that initiates exosome miRNA signaling in cancer cells and may lead to the development of new therapeutic strategies against cancer.

\section{Supplementary information}

Supplementary information accompanies this paper at https://doi.org/10. 1186/s12964-020-00615-9.

Additional file 1: Supplementary Table 1. shRNA oligonucleotide sequences. Supplementary Figure 1. Gene ontology analysis of miR-1246 associated proteins. The enriched $\mathbf{A}$. cellular component and B. molecular function categories of the 593 proteins found to associate with miR-1246. Supplementary Figure 2. Results of the RNAbinding specificities (RBPDB) database analysis of proteins predicted to bind to the mature miR-1246 sequence. Supplement Figure 3. SDSPAGE of purified GST-SRSF1. A total of $5 \mu$ l of lysate or elute was loaded per lane. The gel was stained with Coomassie blue dye. Supplementary Figure 4. Exosomal miR-1246 levels in EIF3B knockdown PANC-1 cells. A. EIF3B knockdown verified by western blot. B. Exosomal miR-1246 in EIF3B knockdown PANC-1 cells. Supplementary Figure 5. Exosomal miR-1246 in TIA1 knockdown PANC-1 cells. A TIA1 knockdown verified by western blot. B. Exosomal miR-1246 in TIA1 knockdown PANC-1 cells. Supplementary Figure 6. Association of SRSF1's expression level with cancer patient survival. Data were from THE HUMAN PROTEIN ATLAS database: A. SRSF1 expression and survival years in pancreatic cancer patients. B. SRSF1 expression and survival years in liver cancer patients. C. SRSF1 expression and survival years in renal cancer patients.

\section{Abbreviations}

ATCC: American type culture collection; EIF3B: Eukaryotic translation initiation factor 3 subunit B; Co-IP: Co-immunoprecipitation; EMSA: Electrophoretic mobility shift assay; GAPDH: Glyceraldehyde 3-phosphate dehydrogenase; miRNA: MicroRNA; qRT-PCR: Quantitative reverse transcription PCR; RBP: RNA binding protein; RIP: RNA immunoprecipitation; SRSF1: Serine and arginine rich splicing factor 1; TIA1: T cell-restricted intracellular antigen 1

\section{Acknowledgements}

Technical services were provided by the core facility at the Peggy and Charles Stephenson Cancer Center, University of Oklahoma Health Sciences Center. We thank the Laboratory for Molecular Biology and Cytometry Research at OUHSC for the next generation small RNA sequencing and mass spectrometry service (P20GM103447). We appreciate Dr. Virginie Sjoelund's help in providing assistance with the LC-MS analysis.

\section{Authors' contributions}

YX carried out and/or supervised the experiments and drafted the manuscript. XX, AG and JND assisted with cellular assays and western blots. $\mathrm{BNH}, \mathrm{BHMM}$, and $\mathrm{MC}$ participated in the design of the experiments and assisted with drafting the manuscript. WQD conceived of the study and participated in its design and coordination, and finalized the manuscript. The authors read and approved the final manuscript.

\section{Author's information}

Not applicable.

\section{Funding}

This study was supported in part by grants from the National Institute of General Medical Sciences of the National Institutes of Health (U54GM104938, P20GM103640), the National Cancer Institute (CA235208-01), the Oklahoma Center for the Advancement of Science and Technology (HR14-147), the
Presbyterian Health Foundation, and the Peggy and Charles Stephenson Cancer Center.

\section{Availability of data and materials}

The data generated or analyzed during this study are included in this manuscript and its supplementary files or are available from the corresponding author on reasonable request.

Ethics approval and consent to participate

Not applicable.

\section{Consent for publication}

All authors have read this manuscript and approved for the submission.

\section{Competing interests}

The authors declare that they have no competing interests.

\section{Author details}

${ }^{1}$ Department of Pathology, University of Oklahoma Health Sciences Center, Oklahoma City, 940 Stanton L. Young Blvd., BMSB 401A, Oklahoma City, OK 73104, USA. ${ }^{2}$ Department of General Surgery, First People's Hospital of Taicang City, Taicang Affiliated Hospital of Soochow University, Suzhou 215400, China. ${ }^{3}$ Department of Biochemistry and Molecular Biology, University of Oklahoma Health Sciences Center, Oklahoma City, OK 73104, USA. ${ }^{4}$ Charles E. Schmidt College of Medicine, Florida Atlantic University, Boca Raton, FL 33431, USA. ${ }^{5}$ Department of Obstetrics and Gynecology, Section of Gynecologic Oncology, Stephenson Cancer Center, College of Medicine, University of Oklahoma Health Sciences Center, Oklahoma City, OK 73103, USA. ${ }^{6}$ Stephenson Cancer Center, University of Oklahoma Health Sciences Center, Oklahoma City, OK 73104, USA.

Received: 7 January 2020 Accepted: 27 June 2020

Published online: 20 August 2020

\section{References}

1. Hannafon BN, Ding WQ. Intercellular communication by exosome-derived microRNAs in cancer. Int J Mol Sci. 2013;14:14240-69.

2. Friedl $P$, Alexander S. Cancer invasion and the microenvironment: plasticity and reciprocity. Cell. 2011;147:992-1009.

3. Hanahan D, Weinberg RA. Hallmarks of cancer: the next generation. Cell. 2011:144:646-74.

4. Keller S, Sanderson MP, Stoeck A, Altevogt P. Exosomes: from biogenesis and secretion to biological function. Immunol Lett. 2006;107:102-8.

5. Zhou W, Fong MY, Min Y, Somlo G, Liu L, Palomares MR, et al. Cancersecreted miR-105 destroys vascular endothelial barriers to promote metastasis. Cancer Cell. 2014;25:501-15.

6. Umezu T, Ohyashiki K, Kuroda M, Ohyashiki JH. Leukemia cell to endothelial cell communication via exosomal miRNAs. Oncogene. 2013;32:2747-55.

7. Ozdemir BC, Pentcheva-Hoang T, Carstens JL, Zheng X, Wu CC, Simpson TR, et al. Depletion of carcinoma-associated fibroblasts and fibrosis induces immunosuppression and accelerates pancreas cancer with reduced survival. Cancer Cell. 2014:25:719-34.

8. Paggetti J, Haderk F, Seiffert M, Janji B, Distler U, Ammerlaan W, et al. Exosomes released by chronic lymphocytic leukemia cells induce the transition of stromal cells into cancer-associated fibroblasts. Blood. 2015;126: 1106-17.

9. Thery C, Ostrowski M, Segura E. Membrane vesicles as conveyors of immune responses. Nat Rev Immunol. 2009:9:581-93.

10. Yu S, Liu C, Su K, Wang J, Liu Y, Zhang L, et al. Tumor exosomes inhibit differentiation of bone marrow dendritic cells. J Immunol. 2007;178:6867-75.

11. Becker A, Thakur BK, Weiss JM, Kim HS, Peinado H, Lyden D. Extracellular vesicles in cancer: cell-to-cell mediators of metastasis. Cancer Cell. 2016;30: 836-48.

12. Peinado $H$, Zhang $H$, Matei $I R$, Costa-Silva B, Hoshino A, Rodrigues $G$, et al. Pre-metastatic niches: organ-specific homes for metastases. Nat Rev Cancer. 2017;17:302-17

13. Hannafon BN, Carpenter KJ, Berry WL, Janknecht R, Dooley WC, Ding WQ. Exosome-mediated microRNA signaling from breast cancer cells is altered by the anti-angiogenesis agent docosahexaenoic acid (DHA). Mol Cancer. 2015;14:133 
14. Tkach $M$, Thery $C$. Communication by extracellular vesicles: where we are and where we need to go. Cell. 2016;164:1226-32.

15. Su MJ, Aldawsari H, Amiji M. Pancreatic cancer cell exosome-mediated macrophage reprogramming and the role of MicroRNAs 155 and 125b2 transfection using nanoparticle delivery systems. Sci Rep. 2016;6:30110.

16. Thind A, Wilson C. Exosomal miRNAs as cancer biomarkers and therapeutic targets. J Extracell Vesicles. 2016;5:31292.

17. Pitt JM, Kroemer G, Zitvogel L. Extracellular vesicles: masters of intercellular communication and potential clinical interventions. J Clin Invest. 2016;126: $1139-43$.

18. Mirzaei H, Sahebkar A, Jaafari MR, Goodarzi M, Mirzaei HR. Diagnostic and therapeutic potential of exosomes in cancer: the beginning of a new tale? J Cell Physiol. 2017; 232:3251-60.

19. Hannafon BN, Trigoso YD, Calloway CL, Zhao YD, Lum DH, Welm AL, et al. Plasma exosome microRNAs are indicative of breast cancer. Breast Cancer Res. 2016;18:90.

20. Pigati L, Yaddanapudi SC, lyengar R, Kim DJ, Hearn SA, Danforth D, et al. Selective release of microRNA species from normal and malignant mammary epithelial cells. PLoS One. 2010;5:e13515.

21. Xu YF, Hannafon BN, Zhao YD, Postier RG, Ding WQ. Plasma exosome miR$196 a$ and miR-1246 are potential indicators of localized pancreatic cancer. Oncotarget. 2017;8:77028-40.

22. Zhang J, Li S, Li L, Li M, Guo C, Yao J, et al. Exosome and exosomal microRNA: trafficking, sorting, and function. Genomics Proteomics Bioinformatics. 2015;13:17-24.

23. Teng $Y$, Ren $Y$, Hu X, Mu J, Samykutty A, Zhuang X, et al. MVP-mediated exosomal sorting of miR-193a promotes colon cancer progression. Nat Commun. 2017:8:14448.

24. Xu YF, Hannafon BN, Ding WQ. microRNA regulation of human pancreatic cancer stem cells. Stem Cell Investig. 2017;4:5

25. Fong MY, Zhou W, Liu L, Alontaga AY, Chandra M, Ashby J, et al. Breastcancer-secreted miR-122 reprograms glucose metabolism in premetastatic niche to promote metastasis. Nat Cell Biol. 2015;17:183-94.

26. Xu YF, Hannafon BN, Khatri U, Gin A, Ding WQ. The origin of Exosomal miR1246 in human cancer cells. RNA Biol. 2019.

27. Li XJ, Ren ZJ, Tang JH, Yu Q. Exosomal MicroRNA MiR-1246 promotes cell proliferation, invasion and drug resistance by targeting CCNG2 in breast cancer. Cell Physiol Biochem. 2017;44:1741-8.

28. Sakha S, Muramatsu T, Ueda K, Inazawa J. Exosomal microRNA miR-1246 induces cell motility and invasion through the regulation of DENND2D in oral squamous cell carcinoma. Sci Rep. 2016;6:38750.

29. Villarroya-Beltri C, Gutierrez-Vazquez C, Sanchez-Cabo F, Perez-Hernandez D, Vazquez J, Martin-Cofreces N, et al. Sumoylated hnRNPA2B1 controls the sorting of miRNAs into exosomes through binding to specific motifs. Nat Commun. 2013:4:2980

30. Shurtleff MJ, Temoche-Diaz MM, Karfilis KV, Ri S, Schekman R. Y-box protein 1 is required to sort microRNAs into exosomes in cells and in a cell-free reaction. Elife. 2016:5:e19276.

31. Das S, Krainer AR. Emerging functions of SRSF1, splicing factor and oncoprotein, in RNA metabolism and cancer. Mol Cancer Res. 2014;12:1195204.

32. Wisniewski JR, Zougman A, Nagaraj N, Mann M. Universal sample preparation method for proteome analysis. Nat Methods. 2009;6:359-62.

33. Zhang $X$, Yu H, Lou JR, Zheng J, Zhu H, Popescu NI, et al. MicroRNA-19 (miR-19) regulates tissue factor expression in breast cancer cells. J Biol Chem. 2011;286:1429-35.

34. Baldwin AS Jr. The NF-kappa B and I kappa B proteins: new discoveries and insights. Annu Rev Immunol. 1996;14:649-83.

35. Hannafon BN, Gin AL, Xu YF, Bruns M, Calloway CL, Ding WQ. Metastasisassociated protein 1 (MTA1) is transferred by exosomes and contributes to the regulation of hypoxia and estrogen signaling in breast cancer cells. Cell Commun Signal. 2019;17:13.

36. Paz S, Lu ML, Takata H, Trautmann L, Caputi M. SRSF1 RNA recognition motifs are strong inhibitors of HIV-1 replication. J Virol. 2015;89:6275-86.

37. Huang X, Zheng M, Wang P, Mok BW, Liu S, Lau SY, et al. An NS-segment exonic splicing enhancer regulates influenza a virus replication in mammalian cells. Nat Commun. 2017;8:14751.

38. Bailey TL, Boden M, Buske FA, Frith M, Grant CE, Clementi L, et al. MEME SUITE: tools for motif discovery and searching. Nucleic Acids Res. 2009;37: W202-8.
39. Cook KB, Kazan H, Zuberi K, Morris Q, Hughes TR. RBPDB: a database of RNA-binding specificities. Nucleic Acids Res. 2011:39:D301-8.

40. Rhodes DR, Yu J, Shanker K, Deshpande N, Varambally R, Ghosh D, et al. ONCOMINE: a cancer microarray database and integrated data-mining platform. Neoplasia. 2004;6:1-6.

41. Uhlen M, Fagerberg L, Hallstrom BM, Lindskog C, Oksvold P, Mardinoglu A, et al. Proteomics. Tissue-based map of the human proteome. Science. 2015; 347:1260419.

42. Wickham H. ggplot2, elegant graphics for data analysis: 2016;Springer-Verlag New York, ISBN 978-3-319-24277-4

43. Salehi M, Sharifi M. Exosomal miRNAs as novel cancer biomarkers: challenges and opportunities. J Cell Physiol. 2018;233:6370-80.

44. Sun Z, Shi K, Yang S, Liu J, Zhou Q, Wang G, et al. Effect of exosomal miRNA on cancer biology and clinical applications. Mol Cancer. 2018;17:147.

45. Krainer AR, Conway GC, Kozak D. Purification and characterization of premRNA splicing factor SF2 from HeLa cells. Genes Dev. 1990;4:1158-71.

46. Karni R, de Stanchina E, Lowe SW, Sinha R, Mu D, Krainer AR. The gene encoding the splicing factor SF2/ASF is a proto-oncogene. Nat Struct Mol Biol. 2007;14:185-93.

47. Caceres JF, Screaton GR, Krainer AR. A specific subset of SR proteins shuttles continuously between the nucleus and the cytoplasm. Genes Dev. 1998;12: $55-66$.

48. Wu H, Sun S, Tu K, Gao Y, Xie B, Krainer AR, et al. A splicing-independent function of SF2/ASF in microRNA processing. Mol Cell. 2010;38:67-77.

49. Anczukow O, Rosenberg AZ, Akerman M, Das S, Zhan L, Karni R, et al. The splicing factor SRSF1 regulates apoptosis and proliferation to promote mammary epithelial cell transformation. Nat Struct Mol Biol. 2012;19:220-8.

50. Moradi-Chaleshtori M, Hashemi SM, Soudi S, Bandehpour M, MohammadiYeganeh S. Tumor-derived exosomal microRNAs and proteins as modulators of macrophage function. J Cell Physiol. 2019;234:7970-82.

51. Bell E, Taylor MA. Functional roles for Exosomal MicroRNAs in the tumour microenvironment. Comput Struct Biotechnol J. 2017;15:8-13.

\section{Publisher's Note}

Springer Nature remains neutral with regard to jurisdictional claims in published maps and institutional affiliations.
Ready to submit your research? Choose BMC and benefit from:

- fast, convenient online submission

- thorough peer review by experienced researchers in your field

- rapid publication on acceptance

- support for research data, including large and complex data types

- gold Open Access which fosters wider collaboration and increased citations

- maximum visibility for your research: over $100 \mathrm{M}$ website views per year

At $\mathrm{BMC}$, research is always in progress.

Learn more biomedcentral.com/submissions 